\title{
Introduction to The Review of Regional Studies' First Special Issue on Regional Development in China
}

\author{
Michael L. Lahr
}

When Robert Gibbs and I took over editorial management of this journal in 2007, we had many lofty goals in mind for The Review of Regional Studies. The main one was to continue the journal's excellence achieved under the wardship of our immediate predecessors, Dan Rickman and Ronald Moomaw. When prodded, Dan made it clear that a key to their success was the set of special issues that appeared nearly every year of their tenure as managing editors. We concurred. Another of our many goals was to make an explicit effort to broaden the journal's geographic perspectives. We kicked off this effort by adding a few of our international colleagues to The Review's Editorial Board. This issue became the second part of our effort.

Our idea was that a special issue on China's regional development would expand The Review's international appeal. While truly something Robert and I planned for The Review, it is also the product of a chance confluence of events. The first event, of course, was Robert's invitation for me to join him in editing this journal. The invite by my old grad school chum encouraged me to cordon off a larger share of my time for SRSA concerns. It also enhanced the bundle of incentives that ultimately wound up engaging me in yet another editorial venture. This is critical since such activities appear to yield (for me at least) diminishing returns to scale. The second event was that I met—and was able to work with—Ling Yang. During the preceding year, Ling had applied to work with me, with funding from her national government to be a visiting scholar. She came as a pre-dissertation student with interests in regional income inequality in her home country. Her concern for her country's socioeconomic conditions explains the geographic theme of this issue. The third and final key event was the convening of the $47^{\text {th }}$ Annual Meeting of the Southern Regional Science Association in Arlington, Virginia. Had the meeting been much further afield from our offices in New Jersey, I doubt I would have suggested that Ling present a piece we had been working on. Had Ling not agreed to follow my suggestion, I doubt I would have noticed the surprisingly large number of papers at those meetings that focused on regional issues in China. Had there not been so many papers on such issues, I probably would not have proposed to Ling and Robert the concept of a special issue of The Review focusing on regional development in China. The large number of papers presented at the meetings revealed the SRSA's preference for such material and also identified authors who might wish to contribute to such a special issue.

The upshot of this chance confluence of events was that Ling Yang and I ended up scouting out pertinent sessions of the SRSA's $47^{\text {th }}$ Annual Meetings. It was there that we met and talked with Jiamin Wang and Seong-Hoon Cho, two of the issue's authors, about contributing.

Jiamin Wang offered up two papers for our consideration. It was a generous offer, but given a limit of about six to seven papers per issue in The Review, Robert and I thought it best to have a diversified authorship for the issue. Of the two, we selected the one entitled China's Regional Disparity in Demographic Transition: A Spatial Analysis because it made an ideal lead piece. It is performed in a thorough, yet methodologically simple, manner. Wang discusses trends in fertility, the aging of the population, migration, and household composition by region of China, and how they may have affected differential regional economic growth. The piece by 
Ling Yang and I seems to me to follow naturally from that by Wang. (Then again, I could be biased somewhat on this.)

The paper by Ling Yang and Michael L. Lahr, Labor Productivity Differences in China 1987-1997: An Interregional Decomposition Analysis, is one that I thought would be worthwhile for two reasons. First, prior to arriving stateside, Ling had been focusing on identifying correlates of GDP per capita for China's counties and municipalities. I immediately suggested to her that she needed to take a different tack, because industry mix data were sorely lacking at these levels of geography in China. I tried to convey to her my undergraduate lessons using shiftshare analysis, for it was there that I learned that industry mix tends be the main driver of household income differences across regions and that interregional wage differences for any given industry tend to play a secondary role at best.

I allude above that data available in China for areal units smaller than the provincial level are not generally of the high quality that much of the developed world has come to expect. I cannot be certain of why that should be the case, other than that there may perhaps be strong incentives for local government officials in China to report exuberant GDP figures and too few penalties to ensure that they realistically moderate the reports. Moreover, microdata on China's economy and population are quite parsimonious with respect to both time and space.

In any case, the second reason I thought Ling should investigate the topic of our paper in this issue of The Review was that I (Lahr, 2008) had recently reviewed a book announcing the release of China's second multiregional input-output table. The pair of tables enabled the rather unique opportunity to do a kind of complex shift-share analysis to find out what structures of the economy might be motivating changes in productivity differentials across China's regions. Typically such analyses induce authors to create new and different decomposition approaches. The push to innovate technique means that particular decompositions are rarely if ever replicated. Given that this was to be her entrée into input-output analysis, I suggested that she follow the recipe provided by the only pre-existing structural decomposition analysis piece that examines multiple regions simultaneously—that by Dietzenbacher, Hoehn, and Los (2000).

Our main findings are that modest productivity changes in both the agriculture and transportation sectors, both of which are also low productivity sectors in China, tended to keep productivity levels depressed in China's interior between 1987 and 1997. These findings comport well with those of Wang noted above. Interestingly, they also provide a great segue to the papers in this issue of The Review by Lambert and Cho and by $\mathrm{Li}$, Zeng, and Zhang that immediately follow ours. Both examine China's agricultural economy.

As I mentioned earlier, Seong-Hoon Cho was one of the authors in this issue with whom Ling and I had discussions in Arlington. Ling was assigned to discuss his presentation at those $47^{\text {th }}$ SRSA meetings. It seemed ideal for our project since in it Cho and a few colleagues estimated Cobb-Douglas production functions for a number of crops in China at the county level using geographically weighted regression. They essentially showed that input mix makes a real difference in agricultural performance and that it varies widely across China's vast landscape. Cho informed us, however, that the piece was already being revised for publication elsewhere (Cho et al., 2007). But he promised not to disappoint and proffered a fresh piece that is presented in this issue. In Forecasting Input Demand Shocks on China's Gross Value of Agricultural Output, Dayton Lambert and Seong-Hoon Cho produce a county-level model of spatial processes_-SARAR(1,1) — to examine the extent to which changes in inputs might affect levels 
of agricultural production in China and its spatial distribution. They find that increases in fertilizer and machinery use and in continued emigration of farm labor to cities would generally increase agriculture's contribution to China's GDP. But they do not find Pareto improvement at the county level: they observe some negative spatial autocorrelation.

Ling Yang's advisor at Xi'an Jiaotong University-Guoping $\mathrm{Li}$-was, of course, someone we included as a possible candidate for a contributor to the issue from the get go. I thought her work in regional economics would undoubtedly dovetail nicely into the proposed issue. Plus, I thought it important for the issue to have one or more authors who were actually working from offices in China. When asked, Li provided the manuscript Study of Agricultural Productivity and Its Convergence across China's Regions, co-written with two of her studentsXianfeng Zeng and Lizhen Zhang. Their contribution is a heavily revised version of an article in Mandarin published in the Journal of Quantitative \& Technical Economics (Vol. 25, No. 5).

In the paper, Li, Zeng, and Zhang use data envelopment analysis (DEA) to examine the change in agricultural productivity across 30 of China's provinces and major municipalities, which tended to decline between 1980 and 2005. The application of DEA is particularly apt. As opposed to a Solow-based approach or stochastic frontier analysis, it obviates the need for assumptions affiliated with competitive markets that might not yet be fully in place in China. The authors detect substantial gains in productivity due to technological progress during the period with coastal areas leading the way. Farms in China tend to be small, however, and are likely to remain that way due to physical geographic limitations. As a result, continued gains are likely to be rather modest unless some radical change takes place. Such change is critical if China wants to maintain its self-sufficiency in food goods and also release enough of its farm population to its seemingly ever-growing manufacturing and service sectors so that it can attain growth targets for the overall economy (close to double-digit GDP growth).

Although there were other papers on China presented in Arlington, we did not secure them. Either the papers seemed to Ling and me to be a poor match for the issue we were envisioning, the author(s) were reluctant to give them up, or the author(s) did not believe they could meet our proposed timeline. I apologize here to any readers who fall into this last category, because the fallout of all this was that the timeline had to be changed as we found ourselves tracking down other potential authors. Our main criterion for remaining contributions was that they should be on topics not yet covered by the five we had in hand. Still, we needed two or three pieces to fill the issue. My records show that it took us two months to find and encourage the right people to step up.

Topics that I hoped to see covered in the issue in some way were health care, education, migration, firm location, and gender issues...basically topics that have a tendency to crop up in The Review. My selection was moderated in part by a few presentations I had heard earlier that year at a workshop at Western Ontario University run by John Whalley for young Chinese scholars. Unfortunately, most of the works of these young scholars were just getting underway. So Ling Yang and I undertook an extensive search of recent literature. A Chinese name that tends to pop up frequently in the English language on a few of these topics is Ying $\mathrm{Chu} \mathrm{Ng}$ 's. Indeed, her website expresses her research interests as "Human Capital and Labor Economics, Health Economics and Health Services Research, Economics of Education and Training." And while I had not run across her work previously, her list of publication outlets was quite noteworthy. So we wrote her to see if she would like to join the venture. She graciously (and fortunately) acquiesced. Ng's paper The Productive Efficiency of the Health Care Sector of 
China was a pleasant surprise since she had not previously written on so broad a topic in health care. The fact is, health care remains a very important measure of life quality, and especially so in developing economies.

Like Li, Zeng and Zhang, Ng uses DEA to decompose productivity using Malmquist's index. Interestingly, she finds that while all provinces experienced technological improvement, coastal provinces were less technically efficient in terms of health care. She hints that this may have been caused by the vast sums of cash that only recently have been thrown at the coast and targeted for improving health care.

Our last taker was the SRSA's own Shaoming Cheng. He opted to grant us a peek into his recently published dissertation (Cheng, 2007), which is entitled Preference Heterogeneity and Industrial Location: Location Choices of Japanese FDI in China. In econometric parlance "heterogeneity" implies the use of a mixed logit model, which was developed by Kenneth Train, among others. This type of model allows for random taste variation, unrestricted substitution patterns, and correlation in unobserved factors over time, things not handled by standard logit and probit models. It turns out that Cheng's may be one of the first journal articles on firm location models that uses a mixed logit approach. In a nutshell, he finds that Japanese firms respond in a remarkably homogenous manner to Chinese policy instruments explicitly targeted toward greenfield establishment location. In essence, they tend to cluster near other Japanese establishments. But locations of new Japanese establishments in China are quite sensitive to labor quality. Hence Cheng surmises that labor-based policies could expand the spatial horizons of Japanese investors in China.

Perhaps needless to say, we employed many reviewers and a couple of editorial assistants in pulling this issue together. I thank each of you who were involved. I have already mentioned much of Ling Yang's role, but she also read through each of the papers looking for possible substantive issues that might arise in the mind of a knowledgeable reader. In addition to Robert and me, two others-Samonne Montgomery and Jessica Chao-reviewed the entire set with an eye toward making each paper easier to read. Ling, Samonne, and Jessica, I thank you again, now publicly. While the reviewers of the paper I co-authored must necessarily remain anonymous for now, we thank the following for their thoughts and comments on versions of the various papers: Bernadette Andreosso-O'Callaghan, Zhuo (Adam) Chen, Mingtai Fan, Jin Feng, Fred Gale, Man-Keun Kim, Jørgen Lauridsen, Dayton Lambert, Jim LeSage, Mark Partridge, Yasuhiro Sato, Alexandru Voicu, and Cliff Waldman.

\section{REFERENCES}

Cheng, Shaoming. (2007) Preference Heterogeneity and Industrial Location: Location Choices of Japanese FDI in China. VMD Verlag: Saarbrucken, Germany.

Cho, Seong-Hoon, Zhuo Chen, Steven T. Yen, and Burton C. English. (2007) "Spatial Variation of Output-Input Elasticities: Evidence from Chinese County-level Agricultural Production Data,” Papers in Regional Science, 139-157.

Dietzenbacher, Erik, Alex R. Hoen, and Bart Los. (2000) "Labor Productivity in Western Europe 1975-1985: An Intercountry, Interindustry Analysis,” Journal of Regional Science, 40, 425-452. 
Lahr, Michael L. (2008) "Review of Spatial Structure and Regional Development in China: An Interregional Input-Output Approach, edited by Nobuhiro Okamoto and Takeo Ihara,” Economic Systems Research, 20, 125-128. 